\title{
Time reference in nonfluent and fluent aphasia: A cross-linguistic test of the PAst DIscourse LInking Hypothesis
}

\begin{abstract}
Recent studies by Bastiaanse and colleagues found that time reference is selectively impaired in people with nonfluent agrammatic aphasia, with reference to the past being more difficult to process than reference to the present or to the future. To account for this dissociation, they formulated the PAst DIscourse LInking Hypothesis (PADILIH), which posits that past reference is more demanding than present/future reference because it involves discourselinking. There is some evidence that this hypothesis can be applied to people with fluent aphasia as well. However, the existing evidence for the PADILIH is contradictory, and most of it has been provided by employing a test that predominantly taps retrieval processes, but leaves largely unexplored the underlying ability to encode time reference-related prephonological features. Within a cross-linguistic approach, this study tests the PADILIH by means of a sentence completion task that equally taps encoding and retrieval abilities. This study also investigates if the PADILIH's scope can be extended to fluent aphasia. Greek- and Italian-speaking individuals with aphasia participated in the study. The Greek group consisted of both individuals with agrammatic nonfluent aphasia and individuals with fluent aphasia, who also presented signs of agrammatism. The Italian group consisted of individuals with agrammatic nonfluent aphasia only. The two Greek subgroups performed similarly. Neither language group of participants with aphasia exhibited a pattern of performance consistent with the predictions of the PADILIH. However, a double dissociation observed within the Greek group suggests a hypothesis that may reconcile the present results with the PADILIH.
\end{abstract}

Keywords: time reference, past reference, future reference, encoding, retrieval 


\section{Introduction}

Agrammatic production is primarily characterized by (morpho)syntactic impairment (Goodglass, 1997). Many studies have shown that this impairment is selective, with subjectverb agreement being better preserved than tense and aspect (e.g., Fyndanis, Varlokosta, \& Tsapkini, 2012; Nanousi, Masterson, Druks, \& Atkinson, 2006; Varlokosta, Valeonti, Kakavoulia, Lazaridou, Economou, \& Protopapas, 2006; Wenzlaff \& Clahsen, 2004). Furthermore, recent studies by Bastiaanse and colleagues have shown that also time reference, which is closely related but not identical to tense, is selectively impaired, with reference to the past being more difficult than reference to the present or future (e.g., Bastiaanse, 2008, 2013; Bastiaanse, Bamyaci, Hsu, Lee, Yarbay Duman, \& Thompson, 2011; Dragoy \& Bastiaanse, 2013; Martínez-Ferreiro \& Bastiaanse, 2013; Rofes, Bastiaanse, \& Martínez-Ferreiro, 2014; Yarbay Duman \& Bastiaanse, 2009). The dissociation between past and present/future reference (in particular, the pattern 'past reference $<$ present/future reference') has been reported for many languages, such as Dutch, Turkish, English, Spanish, Catalan, and Russian (op. cit.). To account for this dissociation, Bastiaanse et al. (2011) built on Avrutin (2006) and Zagona (2003, 2013) and put forward the PAst DIscourse LInking Hypothesis (PADILIH). The PADILIH posits that, regardless of whether reference to different time frames is made through monolectic (one-word) or periphrastic verb forms, past reference through verb inflection is selectively impaired in people with agrammatic aphasia because, unlike present and future reference, it involves discourse linking (Zagona, 2003; 2013). (For more details about the PADILIH, see next section.) Interestingly, the dissociation predicted by the PADILIH has also been reported not only for people with nonfluent agrammatic aphasia but also for people with fluent aphasia (e.g., Jonkers \& de Bruin, 2009; Kljajevic \& Bastiaanse, 2011; Bos \& Bastiaanse, 2014; Bos, Dragoy, Avrutin, Iskra, \& Bastiaanse, 2014; Dragoy \& Bastiaanse, 2013). However, several studies on aphasia found no significant differences 
between reference to the past, present, and future (e.g., Burchert, Swoboda-Moll, \& De Bleser, 2005; Faroqi-Shah \& Dickey, 2009; Faroqi-Shah \& Thompson, 2004, 2007; Fyndanis et al., 2012; Wenzlaff \& Clahsen, 2004; for a recent review on this topic, see Faroqi-Shah \& Friedman, 2015).

The present study focuses on time reference in production. Its goal is two-fold:

(1) To test the PADILIH (Bastiaanse et al., 2011) taking a cross-linguistic approach and focusing on production.

(2) To address whether the PADILIH may also apply to people with fluent aphasia.

Related to goal 1, this study seeks to provide convergent evidence for the PADILIH employing a task different to that widely used by the Bastiaanse group (see next section), and by focusing on Greek and Italian aphasia.

The next two sections provide more background information on time reference and PADILIH (Bastiaanse et al., 2011), as well as on the way past and future reference are morphologically encoded in Greek and Italian. This background information motivates our cross-linguistic approach to testing the PADILIH, our focus on Greek and Italian, as well as our methodological choices.

\section{Background on time reference, tense and PADILIH, and further motivation for the study}

Time reference is a semantic category and tense is a grammatical category. Time reference is the semantic counterpart of tense. Tense relates to the morphological component of the verb, and time reference relates to the time-related semantic characteristics of the event that the verb refers to. In many languages, tense is the main grammatical device that enables the speaker to refer to different time frames (e.g., past, present, future). Reichenbach (1947) identified three time points, whose relative position determines the tense of a given verb as well as the time frame (past, present, future) this verb refers to: Point of Speech, which is the 
speaking time, Point of the Event, and Point of Reference. The Point of the Event refers to the time when the event takes place relative to the Point of Reference and to the Point of Speech (before, simultaneously with, or after these time points). In simple past, for example, there is an overlap between the Point of the Event and the Point of Reference, and both time points precede the Point of Speech. On the other hand, in present perfect in languages such as English and Greek, the Point of the Event precedes the Point of Speech and the Point of Reference, and the last two time points overlap. Despite their semantic differences, simple past and present perfect refer to the past. Thus, there is not an one-to-one correspondence between tense and time reference. In reference to the past, the Point of the Event (event time) always precedes the Point of Speech (speaking time or, alternatively, evaluation time), whereas in reference to the future the Point of the Event always follows the Point of Speech. These two time points (as well as the Point of Reference) coincide in reference to the present. According to PADILIH's (Bastiaanse et al., 2011) theoretical framework, since speaking time and event time do not coincide in reference to the past, a relation has to be established between these two time points. This relation is considered to be discourse linked, because it cannot be established intrasententially. In reference to the present, however, where speaking time and event time coincide, the relation between these two time points is considered as a kind of "binding relation", that is, a relation that is established locally (i.e. intrasententially). Hence, reference to the present does not involve discourse linking. Reference to the future does not involve discourse linking either, because it is viewed as a subclass of present reference/tense and, further, because reference to a future time point cannot be made as there is no event yet. ${ }^{1}$ According to Avrutin (2000), unlike intrasentential binding relations (e.g.,

\footnotetext{
${ }^{1}$ The view that present and future reference do not involve discourse linking is debated (see, for example, Fyndanis, Manouilidou, Koufou, Karampekios, \& Tsapakis, 2013, and references therein).
} 
subject-verb agreement), discourse linking (or, alternatively, extrasentential linking) is costly. Hence, it is impaired in people with agrammatic aphasia.

Even though most studies on time reference have focused on people with nonfluent agrammatic aphasia, there is some evidence that the PADILIH may also apply to people with fluent aphasia. For example, Jonkers and de Bruin (2009), Kljajevic and Bastiaanse (2011), Bos and Bastiaanse (2014), and Dragoy and Bastiaanse (2013) found that people with fluent aphasia fare worse on past reference than on non-past reference, although their error patterns differ from those of people with nonfluent aphasia. Bos and Bastiaanse (2014) and Kljajevic and Bastiaanse (2011) found that participants with fluent aphasia predominantly made 'within-target-time-frame' errors (e.g., they substituted the imperfective past tense for the perfective past tense) and participants with nonfluent aphasia predominantly made 'outsidetarget-time-frame' errors (e.g., they produced the present tense instead of the perfective past tense). The authors assumed that within-target-time-frame-errors point to a deficit in retrieval processes, whereas outside-target-time-frame-errors point to a deficit in encoding.

It has to be noted here that encoding and retrieval constitute two major components of the time reference process. For example, in order to refer to an event (e.g., writing) that took place before the speaking time, the speaker must encode the abstract prephonological (or diacritic) feature (e.g., PAST) of the to be-produced verb (to write) and subsequently retrieve the corresponding phonological form of the verb (e.g., wrote). (For more details, see FaroqiShah \& Thompson, 2007, and references therein.) However, it is not clear that 'within-targettime-frame' errors and 'outside-target-time-frame' errors result from damage to distinct components, as suggested by Bos and Bastiaanse (2014) and Kljajevic and Bastiaanse (2011). Both error types might stem from damage to either the encoding or the retrieval component of the time reference process. The discourse linking process involved in past reference may 
increase the demands of grammatical encoding. This may result either in incorrect encoding, or in correct encoding at the expense of correct verb form retrieval.

'Outside-target-time-frame' errors could not be attributed to encoding problems only, especially within the context of the Test for Assessing Reference of Time (TART) (Bastiaanse, Jonkers, \& Thompson, 2008), widely used by Bastiaanse's group. In the production part of the TART, the participant is presented with two horizontally-arranged pictures, each accompanied by the infinitival form of a verb. The experimenter initially points to the picture on the left and describes it (e.g., For this picture, you can say the man just ate an apple), then points to the picture on the right and starts to describe it. At some point the experimenter interrupts the utterance and the participant is required to complete it by providing the missing verb phrase, which includes the target finite verb form (e.g., For this picture, you can say the man just... (target: ...peeled an apple) $)^{2}$. The TART, therefore, tests participants' ability to "copy and paste" the tense/time reference feature from the source sentence to the target sentence, and to retrieve the corresponding verb form/inflection. It appears, thus, that the TART predominantly taps into retrieval processes. Certainly, a test focusing on retrieval processes was needed, as it has been argued that it is the retrieval processes that are predominantly impaired in agrammatic aphasia (Faroqi-Shah \& Thompson, 2007; Fyndanis et al., 2012). However, although the predictions of the PADILIH would seem to hold regardless of whether encoding or retrieval processes are affected, the bulk of evidence for the hypothesis has been provided by employing the TART in different languages (see Bastiaanse, 2013, and references therein), which leaves largely unexplored the ability of people with aphasia to encode prephonological features related to time reference (see FaroqiShah \& Thompson, 2007, and references therein).

\footnotetext{
${ }^{2}$ Examples taken from Bastiaanse (2013: 250) (Fig. 2).
} 
Studies reporting results that are at odds with the PADILIH, such as those of Burchert et al. (2005), Faroqi-Shah and Dickey (2009), Faroqi-Shah and Thompson (2004, 2007), and Fyndanis et al. (2012), employed methods other than the TART, which tapped to a comparable extent into encoding of abstract prephonological features and retrieval of the corresponding inflections or verb forms. For example, the transformational sentence completion tasks described in Fyndanis et al.'s (2012) study on Greek agrammatic aphasia assessed participants' ability not to "copy and paste" the tense/time reference feature from the source sentence to the target sentence (and subsequently retrieve the corresponding verb form/inflection), but to make a transition from one tense/time reference feature (present in the source sentence) to another tense/time reference feature on the basis of a cue (temporal adverbial). For instance, in the past reference condition of the sentence completion task described in Fyndanis et al. (2012), the participant heard a source sentence including a futuretensed verb (e.g., Tomorrow you will wash your hair) and had to complete the target sentence producing the past-tense form of the same verb (i.e. washed), because the preverbal material in the target sentence included the adverb yesterday. (i.e. Yesterday you .)

The present study investigates the validity of the PADILIH (Bastiaanse et al., 2011) by "equally" considering the encoding and retrieval processes involved in time reference within a cross-linguistic approach. The PADILIH is expected to be valid cross-linguistically, and should be tested in as many languages as possible. Hence, the ability of people with aphasia to refer to different time frames has been tested in several languages (see, for example, Bastiaanse et al., 2013, and references therein). The present study evaluated the ability of Greek- and Italian-speaking people with aphasia to produce verb forms referring to the past and to the future. To our knowledge, no published study properly tested the PADILIH focusing on aphasia data from Greek and Italian. Fyndanis, Varlokosta and Tsapkini (2012) discussed their data in light of the PADILIH, but they only reported on two 
persons with agrammatic aphasia (neither of whom lent support to the PADILIH.) An additional reason for focusing on Greek and Italian is that these two languages differ in the "prototypical" verb-related morphological means of expressing past and future reference (see next section). The PADILIH predicts that reference to the past is more difficult for speakers with agrammatic aphasia than reference to the future, regardless of the verb-related morphological means of expressing reference to these time frames.

\title{
Background on time reference in Greek and Italian
}

In both languages, time reference is made through verb inflection and temporal adverbials. Past reference through verb inflection is predominantly expressed by monolectic verb forms in Greek, and through periphrastic verb forms in spoken Italian in Northern Italy, which is relevant for this study. Future reference, on the other hand, is predominantly made via periphrastic verb forms (i.e. the combination of the particle $\theta a$ with a finite non-past verb form) in Greek, and through monolectic verb forms in Italian (table 1). In both languages, however, reference to the past and reference to the future can be made by both monolectic and periphrastic verb forms (see table 1), including periphrastic verb forms that encode past perfect and future perfect.

\author{
Insert table 1 about here
}

\section{Methods}

\section{Participants}

Overall, 17 individuals with agrammatic aphasia, who were native speakers of Greek 
1

2

3

4

5

6

7

8

9

$(\mathrm{n}=10)$ and Italian $(\mathrm{n}=7)$, and 21 age- and education-matched control participants (10 speakers of Greek, 11 of Italian) took part in the study. All participants gave informed consent in accordance with the Declaration of Helsinki. Demographic, cognitive, and (semi)spontaneous speech data for Greek- and Italian-speaking participants are summarized in table 2 and table 3, respectively. Presence of aphasia and aphasia type for the Greek-speaking participants were diagnosed on the basis of clinical presentation and the published Greek standardized version of the Boston Diagnostic Aphasia Examination-Short Form (BDAE-SF) (Goodglass, Kaplan, \& Barresi, 2001, 2013). The aphasia diagnosis of the Italian patients was based on clinical presentation and the Italian version of the Aachen Aphasia Test (AAT: Luzzatti, Willmes, \& De Bleser, 1996) and on the Batteria per l'Analisi dei Deficit Afasici (BADA; Miceli, Laudanna, \& Capasso, 2006). Specifically, four Italian-speaking patients (P1, P2, P5, P6) completed the AAT only, and three (P3, P4, P7) the BADA only. The Greek group included five participants with nonfluent aphasia (P2, P4, P7, P8, P9) and five with fluent aphasia (P1, P3, P5, P6, P10). The Italian group included only individuals with nonfluent Broca's aphasia. Analysis of (semi)spontaneous speech — elicited through the Cookie Theft and the Stroke Story — showed that all the participants with aphasia had a relatively low proportion of grammatical sentences; in all cases, this was outside the normal range (see tables 2-3). Moreover, mean length of utterance was reduced (outside the normal range) in 16 out of 17 participants with aphasia. A low proportion of grammatical sentences and reduced mean length of utterance have been suggested to be the core features of an agrammatic output (see, for example, Faroqi-Shah \& Thompson, 2004). ${ }^{3}$ The analysis of (semi)spontaneous speech was based on syntactic, semantic and prosodic criteria, following the coding system

\footnotetext{
${ }^{3}$ It is not common for people with fluent aphasia to show signs of agrammatism. Nevertheless, similar cases have already been reported in the aphasia literature (see, for example, Varlokosta et al., 2006).
} 
developed by Thompson, Shapiro, Tait, Jacobs, Schneider, and Ballard (1995).

\title{
Insert table 2 about here
}

\author{
Insert table 3 about here
}

Verbal working memory (WM) tasks were also administered. Verbal WM capacity in our participants was measured via two complex span tasks: the digit ordering span task (based on MacDonald, Almor, Henderson, Kempler, \& Andersen, 2001) and the backward digit span task. These two span tasks have often been used to measure verbal WM in healthy and neurologically impaired participants, as both involve storage and processing components. Moreover, the backward span task has "relatively good psychometric properties in terms of test-retest reliability" (Salis, Kelly, \& Code, 2015: 730). In the digit ordering task, the participant hears a series of digits (e.g., 2, 8, 5, 4) and is asked to immediately report them back in ascending magnitude order $(2,4,5,8)$. In the backward digit span, the participant hears a series of digits (e.g., 2, 8, 5, 4) and is asked to immediately repeat them back in reverse order of presentation $(4,5,8,2)$. For both tasks, the scoring criteria employed by MacDonald et al. (2001) were used, and composite WM scores were calculated, following Waters and Caplan (2003) (see tables 2-3).

\section{Experiment}

Participants listened to 20 items tapping past reference and 20 items tapping future reference. ${ }^{4}$ For each item, they listened to a source sentence and the beginning of the target

\footnotetext{
${ }^{4}$ Sentences were presented orally by the experimenter to the Greek-speaking participants and with the aid of a computer to the Italian-speaking participants. This was so because one of the persons who tested the Italian-speaking participants with aphasia (i.e. the $1^{\text {st }}$ author) was not a
} 
sentence, and were required to complete the target sentence by producing the missing finite verb phrase. The exact instructions given to the participants are provided in Supplemental Material 1. The participant always had to transform the verb form that appeared in the source sentence into a different form, compatible with an adverbial included in the target sentence. Examples of the two conditions in both language versions of the task are given in table 4. (To produce the correct response, therefore, participants had to both encode a time referencerelated prephonological feature different to that encoded in the verb form of the source sentence, and to retrieve the corresponding verb form/inflection.)

Twenty regular transitive two-place verbs (that is, verbs taking one external and one internal argument—_ subject/agent and object/theme, respectively) were used in each language version of the task. Each verb appeared twice: once in a past reference item and once in a future reference item. This task also included 40 items tapping into subject-verb agreement, pseudorandomly interspersed with the time reference items, so that there were never more than three consecutive items tapping into time reference. Agreement items served as fillers. The time reference items were pseudorandomised, so that there were never more than four consecutive occurrences of the same subcondition (past reference or future reference). The order of items was kept constant for all participants.

\section{Insert table 4 about here}

Reference to the present was not tested because temporal adverbials prototypically associated with present reference, such as now and today, commonly used to elicit present-

native speaker of Italian. We recorded, thus, a native speaker of Italian who read out loud the experimental items (without the target verb phrases), and incorporated these audio files into a PowerPoint presentation. 
tensed/present reference verbs, are also compatible with future-tensed/future reference verbs (e.g., Now I will play guitar), making it hard to reliably test reference to the present (Fyndanis et al., 2012). Moreover, present tense likely acts as the default ("unmarked") tense value, which might be due to morphosemantic (e.g., Lapointe, 1985) or psycholinguistic reasons. For example, present tense is acquired earlier than past tense or future tense (e.g., Pizzuto \& Caselli, 1994; Szagun, 1978). As a consequence, better performance on present reference than on past or future reference (in languages in which future reference is made through non present-tensed verbs) could be attributed to the age of acquisition advantage of present tense.

\section{Scoring criteria}

All responses that included a verb form matching the target time frame were scored as correct. Experimental items did not include aspectual adverbials, so both perfective aspect and imperfective aspect verb forms could be used and scored as correct. Note that Greek encodes the distinction between perfective and imperfective aspect in both past and future reference.

\section{Data analysis}

We employed Fisher's exact test for count data and Crawford's t-test (e.g., Crawford \& Garthwaite, 2002) to analyse results at the individual level and fitted generalized mixed-effect regressions to analyse data at the group level (Pinheiro \& Bates, 2000). Since accuracy was coded as a dichotomous variable (correct answer, incorrect answer), generalized mixed models with logit transformation were fitted to the data (Jaeger, 2008). We employed the lme4 package in R (Bates, Maechler, Bolker, \& Walker, 2014) to fit mixed models. Because both control groups performed at ceiling on time reference, we fitted a number of mixed-effect models (including maximal models with random slopes and/or interactions) to the aphasia datasets only (i.e. dataset of Greek-speaking participants with aphasia and dataset 
1

2

3

4

5

6

7

8

9

of Italian-speaking participants with aphasia). We first fitted maximal models (i.e. models including random slopes and/or interactions) and subsequently fitted simpler models (i.e. models without random slopes and/or interactions). To control for practice/fatigue effect and to make sure that there was no interaction between time reference and order of item presentation, the maximal models fitted to the "Greek dataset" and to the "Italian dataset" also included Trial Order $^{5}$ as a covariate, the interaction between Time Reference and Trial Order, and by-Subject random slopes for Trial Order. Model selection was based on the Akaike Information Criterion (see Burnham \& Anderson, 2004).

To address whether the PADILIH (Bastiaanse et al., 2011) applies not only to nonfluent but also to fluent aphasia, we focused on the Greek group, as only this group included both fluent and nonfluent participants with aphasia. The best-fitting model for the Greek dataset, which we report here, included Time Reference (two levels: Past Reference, Future Reference), Aphasia Type (two levels: nonfluent aphasia, fluent aphasia) and Trial Order as fixed effects, the interaction between Time Reference, Aphasia Type and Trial Order, a random intercept for Subjects, a random intercept for Items, and Time Reference as bySubject random slope.

The best-fitting model for the Italian dataset, which we report here, included Time Reference (two levels: Past Reference, Future Reference) and Trial Order as fixed effects, a random intercept for Subjects, a random intercept for Items, Time Reference as by-Subject random slope, and Trial Order as by-Subject random slope.

The results of the model fitted to the Greek dataset (see below) enabled us to merge this dataset with the Italian dataset and fit mixed-effect models also to the combined aphasia dataset. The best-fitting model for the combined dataset included Time Reference (two levels: Past Reference, Future Reference) and Language (two levels: Greek, Italian) as fixed effects,

\footnotetext{
${ }^{5}$ Trial Order was scaled before entering mixed models (see Baayen, 2008).
} 
a random intercept for Subjects, a random intercept for Items, and Time Reference as by-

Subject random slope. A full list of the models fitted to the three datasets ("Greek dataset", "Italian dataset", "combined dataset") is presented in Supplemental Material 2.

\title{
Results
}

Since, as mentioned in the data analysis section, both control groups performed at ceiling on time reference $(100 \%$ correct), their performance will not be considered in the analyses at the group level. However, we compared the overall performance (i.e. performance on all (past and future reference) items) of each participant with aphasia with that of the relevant control group using Crawford's t-test, to check which participants with aphasia were impaired.

Because in both control groups the standard deviation was 0, the program SINGLIMS. EXE could not yield any results. To tackle this problem we arbitrarily added a single error in each relevant dataset (i.e. dataset of Greek-speaking control participants and dataset of Italianspeaking control participants). The results of Crawford's t-test showed that only one of the 10 Greek-speaking participants with aphasia (P5) and one of the seven Italian-speaking participants with aphasia (P3) were not impaired in time reference (Greek P5: Crawford's t = $0.302, p=0.385$; Italian $\mathrm{P} 3: \mathrm{t}=0.288, p=0.389$; in all the remaining comparisons by Crawford's t-test, $p<0.001)$. However, marked variability was observed at the individual level, and especially within the Greek group, where a double dissociation emerged (table 5) between P4, who fared better on past than on future reference, and P6, who exhibited the opposite pattern. In the Italian group, only P2 exhibited a dissociation, faring worse on past than on future reference.

\author{
Insert table 5 about here
}


1

2

3

4

5

6

7

8

9

The group results of the best-fitting models for the Greek and Italian aphasia datasets are given in table 6 and table 7, respectively. In the Greek group, there was no main effect of time reference, aphasia type and trial order, and no interaction between them. In the Italian group, there was no main effect of time reference and trial order either. Thus, the groups of Greekand Italian-speaking participants with aphasia performed comparably on past and future reference (Greek group: 66\% and 70\% correct on past and future reference, respectively; Italian group: $69 \%$ and $76 \%$ correct on past and future reference, respectively) (figure 1). Since there was no effect of aphasia type in the Greek dataset, we also merged the two (Greek and Italian) datasets ${ }^{6}$, to check if the combined dataset yields the same result (that is, no dissociation between past and future reference) and a main effect of language. The results of the best-fitting model for the combined dataset (table 8) showed that there was no main effect of time reference and language.

\author{
Insert table 6 about here \\ Insert table 7 about here \\ Insert figure 1 about here \\ Insert table 8 about here
}

\title{
Error analysis
}

In both groups of participants with aphasia, time frame repetition errors were the most frequent error type, and accounted for a similar proportion of errors (Greek: 91/129, 71\%;

\footnotetext{
${ }^{6}$ We thank an anonymous reviewer for this suggestion.
} 
Italian: 53/77 errors; 69\%). In these responses, the participant repeated the same time reference feature encoded in the verb form of the source sentence. In the Greek group, this error type was more frequent in the participants with nonfluent aphasia. While $93 \%(52 / 56)$ of the errors produced by these participants were repetition-type errors, only 53\% (39/73) of the errors produced by the fluent Greek-speaking participants with aphasia were repetition-type errors (which was nonetheless the most frequent error type for this subgroup of participants). In the nonfluent subgroup, time frame repetition errors were evenly distributed in the past and future reference conditions ( 24 and 28 errors, respectively). This was not the case in the fluent subgroup, however, in which 31 repetition-type errors occurred in the past reference condition and only 8 in the future reference condition. The second most frequent error type for the Greek-speaking participants with fluent aphasia was the use of present tense (25/73 errors; $34 \%$ ). Of the 25 "present-tense errors", 17 occurred in the future reference condition and 8 in the past reference condition.

Of the 53 repetition-type errors observed in the Italian group, 27 occurred in the past reference condition and 26 in the future reference condition. Other error types consisted of morphophonological errors (omission of auxiliary verb or past participle from periphrastic verb forms referring to the past) $(\mathrm{N}=6)$, failures to respond ( 3 in the past reference condition and 4 in the future reference condition), verb omission errors (1 in the past reference and 1 in the future reference condition), substitution of a verb form referring to the past by a presenttensed verb $(\mathrm{N}=3)$, substitution of a verb form referring to the future by an infinitive $(\mathrm{N}=1)$, and "other errors".

\author{
Analysis of "non-time reference errors" \\ The participants with aphasia also made "non-time reference errors", such as lexical \\ substitution errors, agreement, and omission errors. In the group of Greek-speaking
}


participants with aphasia, of the 76 "non-time reference errors" (71 lexical substitutions, 3 agreement errors, 1 phonological paraphasia, and 1 verb omission error), 31 occurred in the past reference condition and 45 in the future reference condition. Of the 15 "non-time reference errors" (6 lexical substitutions, 4 phonological paraphasias, 1 agreement error, and 1 past participle omission error) made by the Italian-speaking participants with aphasia, 5 occurred in the past reference condition and 10 in the future reference condition. Therefore, 91 "non-time reference errors" were produced in total, 36 of which occurred in the past reference condition and 55 in the future reference condition. This difference is significant (Fisher's exact test, $p<0.01$ ).

\section{Discussion}

The goal of this study was two-fold: (1) to test the PADILIH (Bastiaanse et al., 2011), which posits that reference to the past is more impaired in people with agrammatic aphasia than reference to the present or to the future, because it involves discourse linking, which is costly (Zagona, 2003, 2013); (2) to explore if the PADILIH applies not only to nonfluent agrammatic aphasia but also to fluent aphasia. To address goal 1, we took a cross-linguistic approach and administered a transformational sentence completion task tapping past and future reference to Greek- and Italian-speaking people with agrammatic aphasia. To address goal 2, we compared Greek-speaking individuals with nonfluent agrammatic aphasia and with fluent aphasia. We addressed two questions:

(1) Do Greek- and Italian-speaking people with agrammatic aphasia perform worse on past reference than on future reference in production?

(2) Do both nonfluent and fluent Greek-speaking people with aphasia perform worse on past reference than on future reference in production? 
The answer to question 1 is negative, as no main effect of time reference in either (Greek and Italian) group of participants with aphasia was found. Moreover, the combined dataset of (Greek- and Italian-speaking) participants with aphasia yielded the same result (i.e. no dissociation between past and future reference) and no main effect of language. These results do not support the PADILIH (Bastiaanse et al., 2011).

The distribution of "non-time reference errors" (e.g., lexical substitutions, agreement errors, omission errors) in the two time frames was also not consistent with the PADILIH, as these errors occurred more frequently in the future reference than in the past reference condition. As an anonymous reviewer suggested, if the PADILIH were correct in positing that past reference taxes the processing system more than future reference, and given that the task focuses on time reference, in the past reference condition participants with aphasia (who are known to have limited processing resources) would allocate less attention to processes not related to time reference. This would lead to a larger number of "non-time reference errors" in the past reference than in the future reference condition. This was not the case. On the contrary, based on the distribution of "non-time reference errors" between the two time frames one could speculate that future reference taxes the processing system of people with aphasia more than past reference. The data from the analysis of "non-time reference errors", however, are not consistent with the time reference errors, which -at the group level- did not yield any dissociation between past and future reference. We will further discuss data relevant to question 1 after briefly answering question 2 .

The answer to question 2 (Do both nonfluent and fluent Greek-speaking people with aphasia perform worse on past reference than on future reference in production?) is also negative, because in the Greek participants with aphasia there were no main effects of time reference and of aphasia type, and no interaction between the two. That means that the subgroup of nonfluent participants did not differ from the subgroup of fluent participants, and 
that both subgroups performed comparably on past and future reference. Thus, neither subgroup supports the PADILIH (Bastiaanse et al., 2011). This contrasts with reports of a pattern of performance consistent with the predictions made by the PADILIH in people with both nonfluent and fluent aphasia (e.g., Bos \& Bastiaanse, 2014; Dragoy \& Bastiaanse, 2013; Jonkers \& de Bruin, 2009; Kljajevic \& Bastiaanse, 2011).

To return to question 1, a double dissociation was observed within the Greek group. This suggests that different sources of difficulty may differentially affect the ability of people with aphasia to refer to the past or to the future. Past reference may be impaired because it is discourse-linked (Zagona, 2003; 2013) and future reference because it refers to possible worlds, thus involving more abstract representations as compared to past reference. It might also be that the semantic component of tense/time reference is not the only dimension that taxes the processing system of people with aphasia. The semantic components of time reference ( \pm involvement of discourse linking, \pm involvement of abstract representations) may interact with subject-specific factors (e.g., site and volume of lesion, WM capacity, selective deficit in encoding or retrieval processes - see remainder of Discussion) and languagespecific morphological means of encoding time reference in determining the relative difficulty of reference to different time frames. The various sources of difficulty seem to weigh differently across people with aphasia.

Most of the evidence in support of the PADILIH (Bastiaanse et al., 2011) has been provided by studies using the TART (Bastiaanse et al., 2008) - a task that predominantly investigates the ability to retrieve the verb form/inflection corresponding to a given time frame. In contrast, the sentence completion task used in this study tapped both major processes involved in time reference, i.e. encoding and retrieval, to a similar extent. The contradictory results reported here and in studies that used the TART task could be reconciled by hypothesizing that in the retrieval phase past reference is more demanding in terms of 
processing resources than future reference, and in the encoding phase future reference is more difficult than past reference. If the two major processes involved in time reference exhibit opposing patterns of selective difficulty, and assuming that some individuals with aphasia have encoding or retrieval problems only and some have mixed difficulties, opposing dissociations between past and future reference could cancel each other out at the group level, if a critical condition were met; this might happen only if similar numbers of speakers with a selective encoding deficit and of speakers with a selective retrieval deficit were included in the group of participants with aphasia. This hypothesis has to be tested in future research. To tease apart the role of encoding and retrieval processes, an experimental paradigm would have to include a transformational sentence completion task (similar to the one used in this study) and a task similar to the TART (Bastiaanse et al., 2008). Since the transformational sentence completion task taps into encoding and retrieval processes to a similar extent, whereas the TART predominantly involves retrieval processes, participants with selective encoding problems should fare significantly better on the TART than on the transformational sentence completion task, and participants with a selective deficit in retrieval processes should be equally poor on the two tasks. Evidence for the hypothesis would be provided by finding that the participants with a selective retrieval deficit are more impaired in past reference than in future reference, and those with a selective encoding deficit are more impaired in future reference than in past reference.

This account allows to reconcile the results of the present investigation with those of most 'TART studies'. For the time being, it is an ad hoc hypothesis, driven by behavioral observations more than by theoretical motivations. Its evaluation will need an explicit theoretical framework providing principled reasons why past reference should be more taxing on retrieval and future reference on encoding processes, and richer empirical data, to be ideally collected employing the method outlined above. 


\section{Discussion of error analysis results}

In all three groups of participants with aphasia, most errors followed a 'time frame repetition' pattern, i.e., they resulted in the production of an incorrect verb form which referred to the same time frame as the verb form in the source sentence.

This result could be accounted for within the framework of the Inclusive Working Memory (WM) model (e.g., Unsworth \& Engle, 2007; Unsworth \& Spillers, 2010). The term Inclusive WM was coined by Cowan (2017) to denote the fact that WM involves both temporary storage for ongoing processing and long-term memory retrieval, both requiring allocation of attention. This conceptualization of WM was driven by Unsworth and Engle's (2007) findings that performance on complex span tasks (such as the digit ordering span task and the digit backward span task used here) relates to individual differences both in attention-related processing and in cue-based search in long-term memory. (Note that, despite the different conceptualizations and definitions of WM, there is a general consensus that complex span tasks, such as those used in our study, measure WM (Cowan, 2017; Wright \& Fergadiotis, 2012).)

The high frequency of repetition-type errors could be attributed to the synergistic effect of three factors: task demands, time reference demands, and limited WM capacity (=reduced attentional control and limited storage and processing capacity) of people with aphasia (see WM scores in tables 2-3, and Wright \& Fergadiotis, 2012, and references therein). The task used in this study required attentional control as well as storage and processing resources, both in the past reference and in the future reference condition. Attentional control is needed to inhibit (or suppress) the non-target value of the relevant feature encoded in the verb form in the source sentence. For instance, in our task, the relevant feature is Time Reference and its values are PAST and FUTURE. One of these two values is encoded in the verb form that 
appears in the source sentence. For example, in the source sentence La cuoca ieri ha preparato la cena 'Yesterday the cook prepared the dinner' the prephonological feature PAST is encoded. The participant must inhibit a response that encodes the same value. Therefore, in the target sentence La cuoca domani 'Tomorrow the cook , which

follows the source sentence above, the participant must avoid producing a verb form referring to the past. Within Unsworth and Engle's (2007) WM framework, allocation of continued attention also allows storage of information for ongoing processing and cue-based retrieval from long-term memory. In this task, storage is needed to maintain the lemma representation of the verb in the source sentence (i.e., preparare 'to prepare', in the example above) and the relevant value of the grammatical feature carried by the preverbal material (time reference value) in the target sentence (i.e., future). Lastly, processing resources are needed both for encoding the value of the time reference-related prephonological feature (i.e., FUTURE) and for retrieving the corresponding verb form (i.e., preparerà 'will prepare') from long-term memory. The fact that most incorrect responses consisted of time frame repetitions suggests that, in this task, increased demand for attentional resources exceeded the capacity of participants with aphasia. In other words, the poor performance of our participants on time reference partly stemmed from the taxed attentional component of the "inclusive WM" system, which in turn led to incorrect retrieval (of verb forms) from long-term memory.

\section{Clinical implications}

The present findings also have clinical implications. Both the group and the individual data suggest that treatment programs should target time reference in general, not only reference to the past as one would assume on the basis of the PADILIH (Bastiaanse et al., 2011). Moreover, the error analysis showed that Inclusive WM (Cowan, 2017; Unsworth \& Engle, 2007; Unsworth \& Spillers, 2010) may be critically involved in verb-related 
morphosyntactic production. This is in consistent with recent findings about the role of WM in verb-related morphosyntactic production (e.g., Fyndanis, Arcara, Christidou, \& Caplan, in press; Kok, van Doorn, \& Kolk, 2007). This suggests that cognitive training targeted to WM and attentional control should improve production, at least in the domain of time reference. To date only the effects of cognitive training on sentence comprehension have been explored, with promising results (e.g., Salis, 2012; Zakariás, Keresztes, Marton, \& Wartenburger, 2016). Future research should investigate the impact of cognitive training on verb-related morphosyntactic/morphosemantic production with a focus on time reference.

\section{Conclusion}

This study investigated the ability of Greek- and Italian-speaking individuals with aphasia to refer to the past and to the future through verb inflection. A transformational sentence completion task was employed, which tapped into both encoding and retrieval abilities. Both groups were impaired in time reference. At the group level, Greek and Italian participants with aphasia did not exhibit dissociations between past and future reference. A double dissociation emerged within the Greek group. Regardless of language, group-level analyses do not support the PADILIH (Bastiaanse et al., 2011). However, in the light of the contrasting outcomes of our investigation and of the TART-based studies supporting the PADILIH, and given the different features of the task used here and the TART (Bastiaanse et al., 2008), the double dissociation observed at the single-subject level within the Greek group invites to consider the possibility that future reference poses greater demands on encoding processes and past reference on retrieval processes. This hypothesis should be tested in future research.

Lastly, error analysis shows that dimensions such as attentional control, as well as storage and processing capacity ('Inclusive WM'; Cowan, 2017; Unsworth \& Engle, 2007; Unsworth 
\& Spillers, 2010) are critically involved in producing time reference, at least in the context of transformational sentence completion tasks.

\section{Acknowledgments}

This section will be written after the paper has been accepted. This is so because this section includes identifying information. We wouldn't like to waive our right to a blinded review.

\section{Declaration of Interest}

The authors report no conflicts of interest.

\section{Funding}

This section will be written after the paper has been accepted.

\section{References}

Avrutin, S. (2000). Comprehension of discourse-linked and non-discourse-linked questions by children and Broca's aphasics. In Y. Grodzinsky, L. Shapiro, \& D. Swinney (Eds.), Language and the Brain: Representation and Processing (pp. 295-313). San Diego: Academic Press.

Avrutin, S. (2006). Weak syntax. In Y. Grodzinsky, \& K. Amunts (Eds.), Broca's region (pp. 49-62). Oxford: Oxford University Press.

Baayen, R. H. (2008). Analyzing linguistic data: A practical introduction to statistics using $R$. Cambridge: Cambridge University Press.

Bastiaanse, R. (2008). Production of verbs in base position by Dutch agrammatic speakers: Inflection versus finiteness. Journal of Neurolinguistics, 21, 104-119.

Bastiaanse, R. (2013). Why reference to the past is difficult for agrammatic speakers. Clinical 
Linguistics \& Phonetics, 27, 244-263.

Bastiaanse, R., Bamyaci, E., Hsu, C., Lee, J., Yarbay Duman, T., \& Thompson, C.K. (2011).

Time reference in agrammatic aphasia: A cross-linguistic study. Journal of Neurolinguistics, 24, 652-673.

Bastiaanse, R., Jonkers, R., \& Thompson, C.K. (2008). Test for Assessment of Reference of Time (TART). Groningen: University of Groningen.

Bates, D., Maechler, M., Bolker, B., \& Walker, S. (2014). lme4: Linear mixed-effects models using Eigen and S4. R package version 1.1-6. http://CRAN.R project.org $/$ package $=\operatorname{lme} 4$

Bock, J.K., \& Levelt, W.J.M. (2002). Language production: Grammatical encoding. In G.T.M. Altmann (Ed.), Psycholinguistics: Critical Concepts in Psychology, vol. 5 (pp. 405-452). London: Routledge.

Bos, L., \& Bastiaanse, R. (2014). Time reference decoupled from tense in agrammatic and fluent aphasia. Aphasiology, 28, 533-553. doi: 10.1080/02687038.2014.886322

Bos, L.S., Dragoy, O., Avrutin, S., Iskra, E., \& Bastiaanse, R. (2014). Understanding discourse-linked elements in aphasia: A threefold study in Russian. Neuropsychologia, 57, 20-28. doi: 10.1016/j.neuropsychologia.2014.02.017

Burchert, F., Swoboda-Moll, M., \& De Bleser, R. (2005). Tense and agreement dissociations in German agrammatic speakers: Underspecification vs. hierarchy. Brain and Language, 94, 188-199. doi: 10.1016/j.bandl.2004.12.006

Burnham, K.P., \& Anderson, D.R. (2004). Multimodel inference: Understanding AIC and BIC in model selection. Sociological Methods and Research, 33, 261-304. doi: $10.1177 / 0049124104268644$

Cowan, N. (2017). The many faces of working memory and short-term storage. Psychonomic Bulletin \& Review, 24, 1158-1170. doi: 10.3758/s13423-016-1191-6 
Crawford, J.R., \& Garthwaite, P.H. (2002). Investigation of the single case in neuropsychology: Confidence limits on the abnormality of test scores and test score differences. Neuropsychologia, 40, 1196-1208. doi: 10.1016/S0028-3932(01)00224-X

Dragoy, O., \& Bastiaanse, R. (2013). Aspects of time: Time reference and aspect production in Russian aphasic speakers. Journal of Neurolinguistics, 26, 113-128. doi: 10.1016/j.jneuroling.2012.05.003

Faroqi-Shah, Y., \& Dickey, M.W. (2009). On-line processing of tense and temporality in agrammatic aphasia. Brain and Language, 108, 97-111. doi: 10.1016/j.bandl.2008.10.003

Faroqi-Shah, Y., \& Friedman, L. (2015). Production of verb tense in agrammatic aphasia: A meta-analysis and further data. Behavioural Neurology, vol. 2015, article ID 983870, 15 pages. doi: $10.1155 / 2015 / 983870$

Faroqi-Shah, Y., \& Thompson, C.K. (2004). Semantic, lexical, and phonological influences on the production of verb inflections in agrammatic aphasia. Brain and Language, 89, 484-498. doi: 10.1016/j.bandl.2003.12.006

Faroqi-Shah, Y., \& Thompson, C.K. (2007). Verb inflections in agrammatic aphasia: Encoding of tense features. Journal of Memory and Language, 56, 129-151. doi: 10.1016/j.jml.2006.09.005

Friedmann, N., \& Grodzinsky, Y. (1997). Tense and Agreement in agrammatic production: Pruning the syntactic tree. Brain and Language, 56, 397-425. doi: 10.1006/brln.1997.1795

Fyndanis, V., Arcara, G., Christidou, P., \& Caplan, D. (in press). Morphosyntactic production and verbal working memory: Evidence from Greek aphasia and healthy aging. Journal of Speech, Language and Hearing Research.

Fyndanis, V., Manouilidou, C., Koufou, E., Karampekios, S., \& Tsapakis, E.M. (2013). 
Agrammatic patterns in Alzheimer's disease: Evidence from tense, agreement, and aspect. Aphasiology, 27, 178-200. doi: 10.1080/02687038.2012.705814

Fyndanis, V., Galiussi, F., \& Christidou, P. (2014). A database of Greek-speaking neurologically healthy individuals' (semi)spontaneous speech. Unpublished database.

Goodglass, H. (1997). Agrammatism in aphasiology. Clinical Neuroscience, 4, 51-56.

Goodglass, H., Kaplan, E., \& Barresi, B. (2001). Boston Diagnostic Aphasia Examination: Short Form Record Booklet, 3rd ed. Boston, MA: Lippincott Williams and Wilkins.

Goodglass, H., Kaplan, E., \& Barresi, B. (2013). The Assessment of Aphasia and related disorders: Adaptation and Validation of the Boston Diagnostic Aphasia Examination Short Form in Greek. [Eds: L. Messinis, A. Kastellakis, E. Panagea, \& $\quad$ P. Papathanasopoulos] Patra: Gotsis. (in Greek)

Jaeger, T.F. (2008). Categorical data analysis: Away from ANOVAs (transformation or not) and towards logit mixed models. Journal of Memory and Language, 59, 434-446. doi: 10.1016/j.jml.2007.11.007

Jonkers, R., \& de Bruin, A. (2009). Tense processing in Broca's and Wernicke's aphasia. Aphasiology, 23, 1252-1265. doi: 10.1080/02687030802289192

Kljajevic, V., \& Bastiaanse, R. (2011). Time reference in fluent aphasia: Evidence from Serbian. In A. Vatakis, A. Esposito, M. Giagkou, F. Cummins, \& G. Papadelis (Eds.), Multidisciplinary aspects of time and time perception, vol. 6789 (pp. 258-274). Berlin/Heidelberg: Springer.

Kok, P., van Doorn, A., \& Kolk, H. (2007). Inflection and computational load in agrammatic speech. Brain and Language, 102, 273-283. doi: 10.1016/j.bandl.2007.03.001

Lapointe, S.G. (1985). A theory of verb form use in the speech of agrammatic aphasics. Brain and Language, 24, 100-155. doi: 10.1016/0093-934X(85)90100-2 
Luzzatti, C., Willmes, W., \& De Bleser, R. (1996). Aachener Aphasia Test (AAT): Versione Italiana, 2nd ed. Florence: Organizzazioni Speciali.

MacDonald, M.C., Almor, A., Henderson, V.W., Kempler, D., \& Andersen, E.S. (2001). Assessing working memory and language comprehension in Alzheimer's disease. Brain and Language, 78, 17-42. doi: 10.1006/brln.2000.2436

Martínez-Ferreiro, S., \& Bastiaanse, R. (2013). Time reference in Spanish and Catalan non fluent aphasia. Lingua, 137, 88-105. doi: 10.1016/j.lingua.2013.09.003

Miceli, G., Laudanna, A., \& Capasso, R. (2006). Batteria per l'analisi dei deficit afasici: $B A D A$. Bologna: EMS.

Nanousi, V., Masterson, J., Druks, J., \& Atkinson, M. (2006). Interpretable vs. uninterpretable features: Evidence from six Greek-speaking agrammatic patients. Journal of Neurolinguistics, 19, 209-238. doi: 10.1016/j.jneuroling.2005.11.003

Pinheiro, J.C., \& Bates, D.M. (2000). Mixed-effects models in S and S-PLUS, Statistics and Computing. New York: Springer.

Pizzuto, E., \& Caselli, M.C. (1994). The acquisition of Italian verb morphology in a crosslinguistic perspective. In Y. Levy (Ed.), Other Children, Other Languages: Issues in the Theory of Language Acquisition (pp. 137-188). Hillsdale, NJ: Lawrence Erlbaum Associates.

Reichenbach, H. (1947). Elements of symbolic logic. $1^{\text {st }}$ Free Press paperback, 1966 ed. London: Collier-Macmillan.

Rofes, A., Bastiaanse, R., \& Martínez-Ferreiro, S. (2014). Conditional and future tense impairment in non-fluent aphasia. Aphasiology, 28, 99-115. doi:10.1080/02687038.2013.850650

Salis, C. (2012). Short-term memory treatment: Patterns of learning and generalisation to sentence comprehension in a person with aphasia. Neuropsychological Rehabilitation, 
$22,428-448$.

Salis, C., Kelly, H., \& Code, C. (2015). Assessment and treatment of short-term and working memory impairments in stroke aphasia: A practical tutorial. International Journal of Language \& Communication Disorders, 50, 721-736. doi: 10.1111/14606984.12172

Szagun, G. (1978). On the frequency of use of tenses in English and German children's spontaneous speech. Child Development, 49, 898-901. doi: 10.2307/1128267

Thompson, C.K., Shapiro, L.P., Tait, M.E., Jacobs, B.J., Schneider, S.L., \& Ballard, K.J. (1995). A system for the linguistic analysis of agrammatic language production. Brain and Language, 51, 124-127.

Unsworth, N., \& Engle, R.W. (2007). The nature of individual differences in working memory capacity: Active maintenance in primary memory and controlled search from secondary memory. Psychological Review, 114, 104-132. doi: 10.1037/0033 295X.114.1.104

Unsworth, N., \& Spillers, G.J. (2010). Working memory capacity: Attention control, secondary memory, or both? A direct test of the dual-component model. Journal of Memory and Language, 62, 392-406. doi: 10.1016/j.jml.2010.02.001

Varlokosta, S., Valeonti, N., Kakavoulia, M., Lazaridou, M., Economou, A., \& Protopapas, A. (2006). The breakdown of functional categories in Greek aphasia: evidence from agreement, tense, and aspect. Aphasiology, 20, 723-743. doi:

$10.1080 / 02687030500513703$

Waters, G.S., \& Caplan, D. (2003). The reliability and stability of verbal working memory measures. Behavior Research Methods, Instruments, \& Computers, 35, 550-564. doi: 10.3758/BF03195534

Wenzlaff, M., \& Clahsen, H. (2004). Tense and agreement in German agrammatism. Brain and Language, 89, 57-68. doi: 10.1016/S0093-934X(03)00298-0 
Wright, H.H., \& Fergadiotis, G. (2012). Conceptualizing and measuring working memory and its relationship to aphasia. Aphasiology, 26, 258-278. doi: $10.1080 / 02687038.2011 .604304$

Yarbay Duman, T., \& Bastiaanse, R. (2009). Time reference through verb inflection in Turkish agrammatic aphasia. Brain and Language, 108, 30-39. doi: 10.1016/j.bandl.2008.09.009

Zagona, K. (2003). Tense and anaphora: Is there a tense-specific theory of coreference? In A. Barrs (Ed.), Anaphora: A Reference Guide (pp. 140-171). Oxford: Blackwell Publishing.

Zagona, K. (2013). Tense, aspect, and modality. In M. den Dikken (Ed.), The Cambridge Handbook of Generative Syntax (pp. 746-792). Cambridge: Cambridge University Press.

Zakariás, L., Keresztes, A., Marton, K., \& Wartenburger, I. (2016). Positive effects of a computerized working memory and executive function training on sentence comprehension in aphasia. Neuropsychological Rehabilitation. doi: 10.1080/09602011.2016.1159579 
Table 1. Past and Future Reference in Greek and Italian (for the $1^{\text {st }}$ person, singular number, indicative mood of the verb pézo/giocare 'to play').

\begin{tabular}{|c|c|c|}
\hline & Greek & Italian \\
\hline Past Reference & épeksa (épeza) & ho giocato (giocavo/giocai) \\
\hline Future Reference & $\theta$ a pékso ( $\theta$ a pézo) & giocheró (gioco) \\
\hline
\end{tabular}

Note 1: In Italian, present tense (e.g., gioco) is often used to refer to the future in the presence of a temporal adverbial (e.g., Domani (io) gioco ...').

Note 2: The difference between the Greek verb forms épeksa and épeza, and $\theta a$ pékso and $\theta a$ pézo reflects the opposition perfective vs. imperfective aspect, respectively. Similarly, the Italian verb forms ho giocato/giocai and giocavo encode perfective and imperfective aspect, respectively. 
Table 2. Greek-speaking aphasic and control participants' demographic, cognitive, and selected (semi)spontaneous speech data.

14ognitive 15 variables 16 18 19 ge (years) ${ }_{21}^{2}$ ducation

22years) 23 Handedness

25 tiology 26

\begin{tabular}{|c|c|c|c|c|c|c|c|c|c|c|c|}
\hline P1 & P2 & P3 & P4 & P5 & P6 & P7 & P8 & P9 & P10 & $\begin{array}{l}\text { Aphasic } \\
\text { group (Mean } \\
(\mathrm{SD}) \text { ) }\end{array}$ & $\begin{array}{l}\text { Control group } \\
(\mathrm{N}=10) \\
\text { (Mean (SD)) }\end{array}$ \\
\hline
\end{tabular}

(

F M

72

6

$56 \quad 64$

M

6

12

64

R R

Left

ischaemic

CVA

\section{Right}

hemiplegia

R R

Left

haemorrhagic

CVA

29

Right

hemiplegia
Right

hemiplegia

M F

60

15

F F

66

12

F

74

3

$\mathrm{R}$

Left

R

Left

haemorrhagic

CVA

haemorrhagi ischemic

c CVA

14

\begin{abstract}
CVA
\end{abstract}
13

Right Right

Right

hemiparesis hemiplegia hemiparesis

$\begin{array}{lll}F & F & F \\ 47 & 62 & 79 \\ 12 & 12 & 4\end{array}$

F

90

6

$\mathrm{R}$

Left

ischemic

CVA

18

Right

hemiplegia
$\mathrm{R}$

Left

ischemic

CVA

12

Right

hemiplegia

\section{$\mathrm{R}$}

Left

ischemic

CVA
R

4
$7 \mathrm{~F}, 3 \mathrm{M}$

8 F, 2 M

$67(12.3)$

$67.4(6.6)$

8.8 (4.2)

9.3 (2.6)

All R

All R

Left

ischemic

CVA

$11.2(8.1)$

n.a. 
$5^{\mathrm{H}}$

6

7

8

16

11

12

13

14 15 esion site

16

17

18 omposite WM

Normal

Normal

Normal

Normal

Normal

Normal

Normal/Corre

Normal

Normal

Normal

n.a.

Normal

or

cted to normal

corrected

normal

Conduction

Transcortical Atypical

Broca's Anomic

Wernicke's Broca's

Broca's Broca's

Atypical

n.a.

n.a.

motor aphasia

aphasia aphasia

aphasia

aphasia

aphasia

aphasia

anomic

aphasia

Not available Basal ganglia Not available

Frontal \& Not

Not available Not available

Not

Not available

aphasia

parietal lobe available

available

$10 / 29 \quad 7 / 29$

$10 / 29$

$11 / 29 \quad 2 / 29$

$5 / 29$

$14 / 29$

$9 / 29$

Not available

n.a.

n.a.

20 score

21 anguage variables

22

$23^{W}$ ords per

24 minute

25 
described in Thompson et al. (1995). The (semi)spontaneous speech data of 13 neurologically healthy native speakers of Greek are reported here (mean age $=72.9, \mathrm{SD}=6.2 ;$ mean number of years of formal education $=7.5, \mathrm{SD}=2.5$ )

Note 2: An alternative diagnosis for P3 and P10 would be unclassifiable aphasia. However, we used the term atypical anomic aphasia to highlight the fact that these participants had fluent aphasia. 
Table 3. Italian-speaking aphasic and control participants' demographic, cognitive, and selected (semi)spontaneous speech data.

\begin{tabular}{|c|c|c|c|c|c|c|c|c|c|}
\hline & P1 & P2 & P3 & $\mathrm{P} 4$ & P5 & P6 & P7 & $\begin{array}{l}\text { Aphasic group } \\
\text { (Mean (SD)) }\end{array}$ & $\begin{array}{l}\text { Control group } \\
(\mathrm{N}=11) \\
(\text { Mean }(\mathrm{SD}))\end{array}$ \\
\hline $\begin{array}{l}\text { Demographic \& } \\
\text { cognitive variables }\end{array}$ & & & & & \multicolumn{5}{|c|}{ Demographic \& } \\
\hline Gender & $\mathrm{F}$ & M & $\mathrm{F}$ & M & M & M & $\mathrm{F}$ & $3 \mathrm{~F}, 4 \mathrm{M}$ & $5 \mathrm{~F}, 6 \mathrm{M}$ \\
\hline Age (years) & 55 & 53 & 45 & 77 & 70 & 63 & 43 & $58(12.6)$ & $65.5(10.6)$ \\
\hline Education (years) & 13 & 13 & 13 & 16 & 14 & 18 & 13 & $14.3(2.0)$ & $14.8(4.2)$ \\
\hline Handedness & $\mathrm{R}$ & $\mathrm{R}$ & $\mathrm{R}$ & $\mathrm{R}$ & $\mathrm{R}$ & $\mathrm{R}$ & $\mathrm{R}$ & All R & All R \\
\hline \multirow[t]{3}{*}{ Etiology } & Hemorrhagic & Left & Left & Left & Left & Left & Left & n.a. & n.a. \\
\hline & CVA & ischemic & ischemic & ischemic & ischemic & ischemic & Ischemic & & \\
\hline & & CVA & CVA & CVA & CVA & CVA & CVA & & \\
\hline $\begin{array}{l}\text { Aphasia post-onset } \\
\text { (months) }\end{array}$ & 43 & 101 & 113 & 30 & 286 & 20 & 156 & $107(93.2)$ & n.a. \\
\hline Other conditions & $\begin{array}{l}\text { Right } \\
\text { hemiparesis }\end{array}$ & $\begin{array}{l}\text { Right } \\
\text { hemiparesis }\end{array}$ & $\begin{array}{l}\text { Right } \\
\text { hemiplegia }\end{array}$ & $\begin{array}{l}\text { Very mild } \\
\text { right }\end{array}$ & $\begin{array}{l}\text { Mild right } \\
\text { hemiparesis }\end{array}$ & No & $\begin{array}{l}\text { Right } \\
\text { hemiplegia }\end{array}$ & n.a. & No \\
\hline
\end{tabular}




\begin{tabular}{|c|c|c|c|c|c|c|c|c|c|c|}
\hline \multirow{3}{*}{\multicolumn{2}{|c|}{ Hearing/Vision }} & Normal/ & Normal & Normal/ & Normal/ & Normal/ & Normal & Normal & Normal/Normal & Normal/Normal or \\
\hline & & Corrected to & & Corrected to & Corrected to & Corrected to & & & or corrected to & corrected to \\
\hline & & normal & & normal & normal & normal & & & normal & normal \\
\hline \multirow{2}{*}{\multicolumn{2}{|c|}{ Diagnosis }} & Broca's & Broca's & Broca's & Broca's & Broca's & Broca's & Broca's & n.a. & n.a. \\
\hline & & aphasia & aphasia & aphasia & aphasia & aphasia & aphasia & aphasia & & \\
\hline \multirow{7}{*}{\multicolumn{2}{|c|}{ Lesion site }} & Cortico- & & $\begin{array}{l}\text { CVA in left } \\
\text { superficial }\end{array}$ & Left fronto- & Left frontal & Left Frontal \& & L-FT & n.a. & n.a. \\
\hline & & & & $\begin{array}{l}\& \text { deep } \\
\text { territory of }\end{array}$ & temporo- & involving & Parietal & Insular with & & \\
\hline & & fronto- & fronto- & $\begin{array}{l}\text { MCA } \\
\text { (middle \& }\end{array}$ & parietal & Broca's area \& & & extension & & \\
\hline & & parietal- & temporo- & $\begin{array}{l}\text { inferior } \\
\text { frontal gyri, }\end{array}$ & & immediate & & to $\mathrm{P}$ & & \\
\hline & & Putamen & parietal-insula & $\begin{array}{l}\text { insula, } \\
\text { superficial }\end{array}$ & & surroundings & & & & \\
\hline & & & \& Basal & $\begin{array}{l}\& \text { lateral } \\
\text { aspect of }\end{array}$ & & & & & & \\
\hline & & & ganglia & $\begin{array}{l}\text { temporal } \\
\text { pole, part of } \\
\text { superior \& } \\
\text { middle } \\
\text { temporal } \\
\text { gyrus \& } \\
\text { white matter } \\
\text { of above } \\
\text { structures). }\end{array}$ & & & & & & \\
\hline Composite & WM & $10 / 29$ & $1 / 29$ & $10 / 29$ & $1 / 29$ & $9 / 29$ & $22 / 29$ & $9 / 29$ & $8.9(7.1) / 29$ & $19.5(2.3) / 29$ \\
\hline \multicolumn{11}{|l|}{ score } \\
\hline \multicolumn{11}{|c|}{ Language variables } \\
\hline \multicolumn{2}{|c|}{ Words per minute } & 86.2 & 40.9 & 22.7 & 14.7 & 24.5 & 15.3 & 25.2 & $32.8(25.1)$ & $93.6(28.5)$ \\
\hline
\end{tabular}


1

2

MLU

$\%$ Grammatical

10

sentences

$\begin{array}{llllllll}4.3 & 5.1 & 5.6 & 10.2 & 6.3 & 5.9 & 7.7(2.7) & 16.7(4.6) \\ 20.9 & 39.6 & 10.5 & 34.2 & 12.5 & 76 & 44(24.1) & 91.9(8.5)\end{array}$


Table 4. Examples of the past and future reference conditions of the Greek and Italian versions of the completion task.

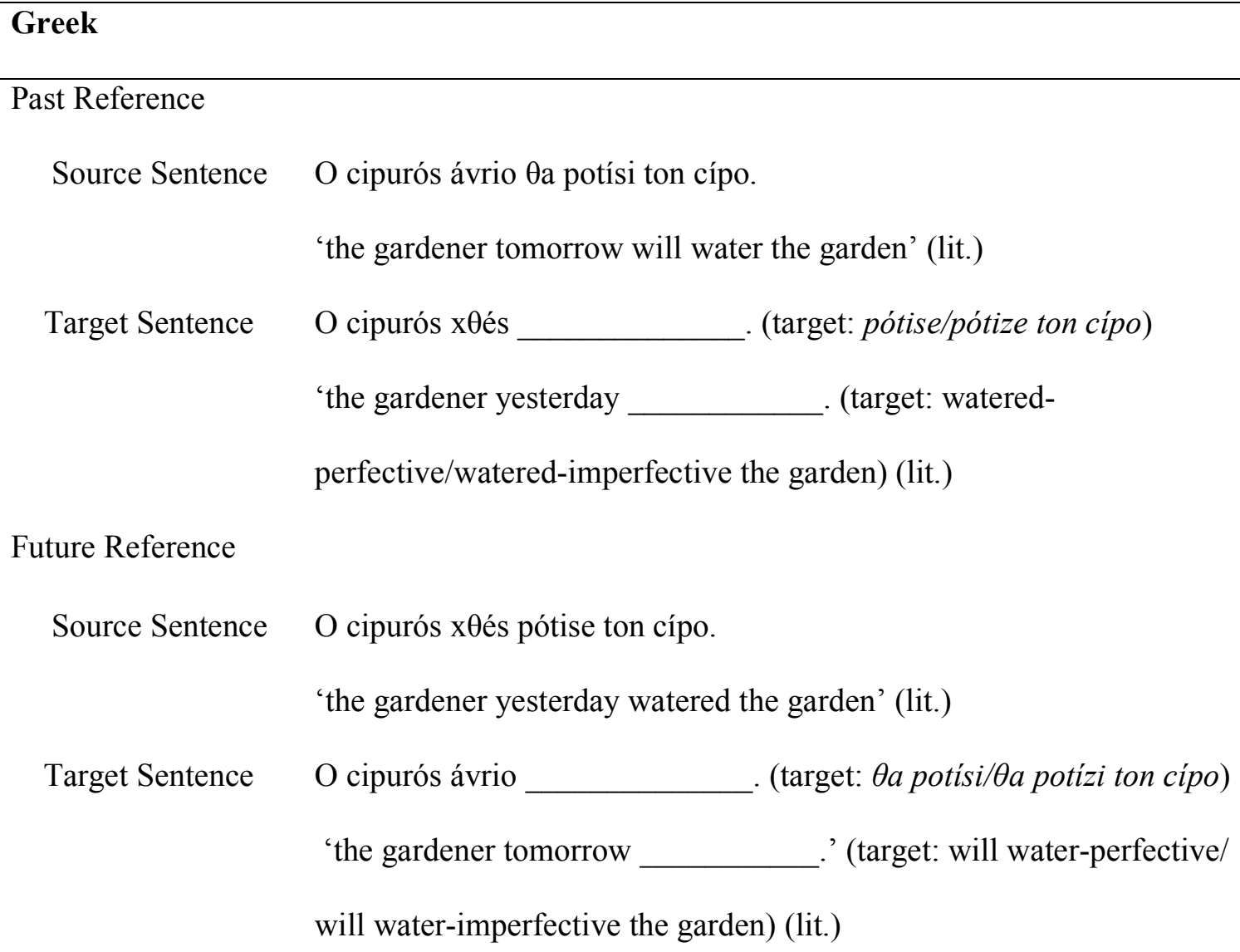

Future Reference

Source Sentence $\quad \mathrm{O}$ cipurós $\mathrm{x}$ és pótise ton cípo.

'the gardener yesterday watered the garden' (lit.)

Target Sentence O cipurós ávrio . (target: $\theta$ a potísi/Oa potízi ton cípo)

'the gardener tomorrow $\therefore$ (target: will water-perfective/

will water-imperfective the garden) (lit.)

\section{Italian}

Past Reference

Source Sentence La cuoca domani preparerà la cena.

'The cook tomorrow will prepare the dinner.' (lit.)

Target Sentence La cuoca ieri . (target: ha preparato/preparò/

preparava la cena)

'The cook yesterday ___ _.' (target: has

prepared/prepared/was preparing the dinner) (lit.)

Future Reference 
Source Sentence La cuoca ieri ha preparato la cena.

'The cook yesterday has prepared the dinner' (lit.)

Target Sentence La cuoca domani ___ _ (target: preparerà/prepara la cena)

'The cook tomorrow ___ _.' (target: will prepare/is preparing the dinner) (lit.)

Note: This table does not include an exhaustive list of the verb forms that could be scored as correct answers. For example, also future perfect and past perfect can be used to refer to the future and past, respectively. 
Table 5. Correct performance (individual count data) of Greek- and Italian-speaking aphasic participants on past and future reference and statistical comparisons using Fisher's exact test for count data.

\begin{tabular}{|c|c|c|c|c|c|c|}
\hline & \multicolumn{2}{|c|}{ Greek } & \multicolumn{4}{|c|}{ Italian } \\
\hline & $\begin{array}{l}\text { Past ref. } \\
(\mathrm{N}=20)\end{array}$ & $\begin{array}{l}\text { Future ref. } \\
(\mathrm{N}=20)\end{array}$ & $\begin{array}{l}\text { Past vs. } \\
\text { future }\end{array}$ & $\begin{array}{l}\text { Past ref. } \\
(\mathrm{N}=20)\end{array}$ & $\begin{array}{l}\text { Future ref. } \\
(\mathrm{N}=20)\end{array}$ & $\begin{array}{l}\text { Past vs. } \\
\text { future }\end{array}$ \\
\hline $\mathrm{P} 1$ & 16 & 16 & $p=1$ & 16 & 17 & $p=1$ \\
\hline $\mathrm{P} 2$ & 19 & 19 & $p=1$ & 7 & 18 & $p<0.001$ \\
\hline P3 & 13 & 14 & $p=1$ & 20 & 20 & $p=1$ \\
\hline P4 & 11 & 1 & $p=.001$ & 15 & 9 & $p=0.105$ \\
\hline P5 & 20 & 20 & $p=1$ & 3 & 8 & $p=0.155$ \\
\hline P6 & 2 & 16 & $p<.001$ & 16 & 18 & $p=0.661$ \\
\hline P7 & 15 & 18 & $p=0.408$ & 19 & 17 & $p=0.605$ \\
\hline P8 & 15 & 16 & $p=1$ & & & \\
\hline P9 & 12 & 18 & $p=0.065$ & & & \\
\hline P10 & 8 & 2 & $p=0.065$ & & & \\
\hline
\end{tabular}


Table 6. Logit mixed-effect model on Greek-speaking aphasic participants’ accuracy.

\begin{tabular}{|c|c|c|c|c|}
\hline Term & $\boldsymbol{\beta}$ & Standard Error & z-value & p-value \\
\hline $\begin{array}{l}\text { (Intercept; Time Ref.=Future Ref, } \\
\text { Aphasia Type=Fluent) }\end{array}$ & 1.384 & 1.111 & 1.246 & 0.213 \\
\hline Time Ref.=Past Ref. & -0.733 & 0.915 & -0.801 & 0.423 \\
\hline Aphasia type $=$ Nonfluent & -0.005 & 1.552 & -0.003 & 0.998 \\
\hline Trial Order & 0.152 & 0.307 & 0.494 & 0.621 \\
\hline $\begin{array}{l}\text { Time Ref.=Past Ref. : Aphasia } \\
\text { type=Nonfluent }\end{array}$ & 0.585 & 1.261 & 0.464 & 0.643 \\
\hline Time Ref.=Past Ref. : Trial Order & -0.632 & 0.406 & -1.557 & 0.120 \\
\hline Aphasia type $=$ Nonfluent $:$ Trial Order & 0.538 & 0.461 & 1.167 & 0.243 \\
\hline $\begin{array}{l}\text { Time Ref.=Past Ref. : Aphasia } \\
\text { type=Nonfluent : Trial Order }\end{array}$ & 0.362 & 0.578 & 0.625 & 0.532 \\
\hline
\end{tabular}

Note 1: This model included Time Reference (two levels: Past Reference, Future Reference), Aphasia Type (two levels: nonfluent aphasia, fluent aphasia) and Trial Order as fixed effects, the interaction between Time Reference, Aphasia Type and Trial Order, a random intercept for Subjects $(\mathrm{SD}=2.312)$, a random intercept for Items $(\mathrm{SD}=0.364)$, and Time Reference as by-Subject random slope.

Note 2: The symbol * indicates significant effects. 
Table 7. Logit mixed-effect model on Italian-speaking aphasic participants' accuracy.

\begin{tabular}{|c|c|c|c|c|}
\hline Term & $\boldsymbol{\beta}$ & Standard Error & z-value & p-value \\
\hline (Intercept; Time Ref.=Future Ref.) & 1.630 & 0.650 & 2.507 & $0.012 *$ \\
\hline Time Ref.=Past Ref. & -0.402 & 0.602 & -0.668 & 0.504 \\
\hline Trial Order & 0.163 & 0.207 & 0.789 & 0.430 \\
\hline \multicolumn{5}{|c|}{ Note 1: The model included Time Reference (two levels: Past Reference, Future Reference) } \\
\hline \multicolumn{5}{|c|}{ and Trial Order as fixed effects, a random intercept for Subjects $(\mathrm{SD}=3.569 \mathrm{e}-01)$, a random } \\
\hline \multicolumn{5}{|c|}{ intercept for Items $(\mathrm{SD}=9.638 \mathrm{e}-05)$, Time Reference as by-Subject random slope, and Trial } \\
\hline Order as by-Subject random slope. & & & & \\
\hline
\end{tabular}


Table 8. Logit mixed-effect model on aphasic participants' accuracy (Greek and Italian data collapsed).

\begin{tabular}{llllc}
\hline Term & $\boldsymbol{\beta}$ & Standard Error & z-value & p-value \\
\hline (Intercept; Time Ref.=Future Ref, & 1.334 & 0.597 & 2.235 & $0.025^{*}$ \\
Language=Greek) & & & & \\
Time Ref.=Past Ref. & -0.418 & 0.431 & -0.970 & 0.332 \\
Language=Italian & 0.332 & 0.817 & 0.406 & 0.685 \\
& & & & \\
\hline
\end{tabular}

Note 1: The model reported here included Time Reference (two levels: Past Reference, Future

Reference) and Language (two levels: Greek, Italian) as fixed effects, a random intercept for

Subjects $(\mathrm{SD}=1.860)$, a random intercept for Items $(\mathrm{SD}=0.254)$, and Time Reference as by-

Subject random slope.

Note 2: The symbol * indicates significant effects. 


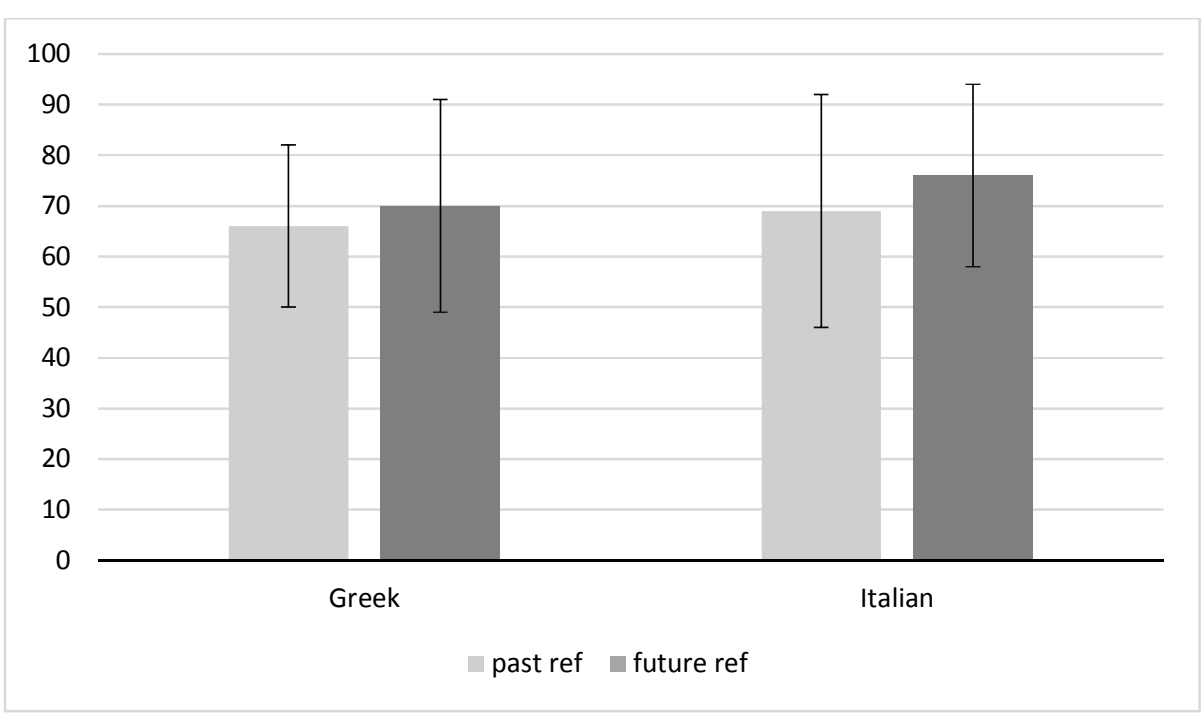

Figure 1. Group results (\% correct) of Greek- and Italian-speaking participants with aphasia. The error bars represent a 95\% confidence interval. 
2

3

4

5

6

7

8

9

10

11

12

13

14

15

16

17

18

19

20

21

22

23

24

25

26

27

28

29

30

31

32

33

34

35

36

37

38

39

40

41

42

43

44

45

46

47

48

49

50

51

52

53

54

55

56

57

58

59

60

\title{
Supplemental Material 1
}

\section{Sentence completion task: Exact instructions given to the participants}

\author{
You will hear a sentence. Then you will hear another sentence, which however will be interrupted at \\ some point. You will have to complete this sentence. For example: \\ Yesterday the grandmother gave out presents. > Tomorrow the grandmother (rising intonation and short \\ pause) ... and you will complete by saying will give out presents
}

Here is one more example:

Tomorrow the electrician will connect the cables. > Yesterday the electrician (rising intonation and short pause)..... connected the cables

One last example, in which you will complete the second sentence: (if the participant makes an error in this example, the experimenter will correct him/her)

Yesterday we played the guitar. > Tomorrow we (target: will play the

guitar)

Great! Ready to start!

URL: http://mc.manuscriptcentral.com/tclp Email: mjb0372@louisiana.edu 


\section{Supplemental Material 2}

We successfully fitted the following three models to the dataset of Greek-speaking participants with aphasia:

(1) glmer(accuracy time_reference*aphasia_type*scaled_trial_order $+(1 \mid$ item $)+(1+$ time_reference|subject), family="binomial")

(2) glmer(accuracy time_reference*aphasia_type+scaled_trial_order $+(1 \mid$ item $)+(1+$ time_reference|subject), family="binomial")

(3) glmer(accuracy time_reference*aphasia_type+scaled_trial_order $+(1 \mid$ item $)+(1 \mid$ subject $)$ , family="binomial")

We successfully fitted the following four models to the dataset of Italian-speaking participants:

(1) glmer(accuracy time_reference+scaled_trial_order $+(1 \mid$ item $)+(1+$ time_reference $\mid$ subje ct $)+(1+$ scaled_trial_order|subject $)$, family="binomial")

(2) $\operatorname{glmer}($ accuracy time_reference + scaled_trial_order $+(1 \mid$ item $)+(1 \mid$ subject $)+(1+$ scaled_trial_order|subject), family="binomial")

(3) glmer(accuracy time_reference+scaled_trial_order $+(1 \mid$ item $)+(1 \mid$ subject $)$, family= "binomial")

(4) glmer(accuracy time_reference* scaled_trial_order $+(1 \mid$ item $)+(1 \mid$ subject $)$, family= "binomial")

We successfully fitted the following three models to the combined dataset of Greek- and Italian-speaking participants with aphasia: 
(1) glmer(accuracy time_reference*language $+(1+$ time_reference $\mid$ subject $)+(1 \mid$ item $)$, family="binomial")

(2) $\operatorname{glmer}\left(\right.$ accuracy time_reference* ${ }^{*}$ language $+(1 \mid$ subject $)+(1 \mid$ item $)$, family="binomial")

(3) glmer(accuracy time_reference+language $+(1+$ time_reference|subject $)+(1 \mid$ item $)$, family="binomial")

(4) glmer(accuracy time_reference+language $+(1 \mid$ subject $)+(1 \mid$ item $)$, family="binomial") 